\title{
DIFERENCIAÇÃO SEXUAL EM JUVENIS DE LIBINIA FERREIRAE (DECAPODA, BRACHYURA), SIMBIONTE DA MEDUSA LYCHNORHIZA LUCERNA
}

\author{
Galiotti, L.L. ${ }^{1,2,}$; Gonçalves, G.R.L. ${ }^{2}$; Belli, C.T. ${ }^{2}$; Castilho, A.L. ${ }^{2}$ \& Negreiros-Fransozo, M.L. ${ }^{2}$
}

1 Universidade Estadual Paulista "Júlio de Mesquita Filho" (UNESP), Faculdade de Ciências, Laboratório de Carcinologia - LABCAM (Laboratório de Biologia de Camarões Marinhos e de Água Doce), Bauru, SP, Brasil.

2 Universidade Estadual Paulista "Júlio de Mesquita Filho" (UNESP), Instituto de Biociências,

Laboratório de Carcinologia - NEBECC (Núcleo de Estudos em Biologia, Ecologia e Cultivo Crustáceos), Botucatu, São Paulo, SP, Brasil.

*Autor correspondente: lucasgaliotti.bio@gmail.com

\begin{abstract}
O caranguejo-aranha Libinia ferreirae Brito Capelo, 1871, comumente capturado na pesca de arrasto ao longo da costa brasileira, em sua fase juvenil, pode ser encontrado em simbiose com medusas pelágicas e na adulta (vida livre) vive no ambiente bentônico. Diversos aspectos da biologia e ecologia de $L$. ferreirae podem ser encontrados na literatura; contudo, a diferenciação sexual dos indivíduos juvenis, ainda, é desconhecida. Este estudo realizou análises sobre morfologia externa, por meio de microscopia de luz, e o crescimento relativo (alométrico) para esclarecer em qual tamanho aparecem os caracteres sexuais secundários em juvenis provenientes da natureza. As estruturas descritas foram as seguintes: pleópodos (ambos os sexos), abdômen (fêmeas) e quelípodo maior (machos). Os animais foram capturados com barco camaroeiro, na região de Cananéia (Estado de São Paulo). As medusas capturadas foram inspecionadas e os caranguejos juvenis, retirados para análises. Os caranguejos juvenis foram medidos quanto à largura (LC) e comprimento (CC) da carapaça; largura do abdômen (LA); e também, altura (AP) e comprimento (CP) do própodo. O menor juvenil (ainda não diferenciado quanto ao sexo = NS) foi completamente desenhado e descrito. Para os tamanhos subsequentes, os desenhos e as descrições foram feitas somente quanto aos caracteres sexuais secundários. Ao longo das amostragens obteve-se um total de 91 juvenis. Caranguejos juvenis, com tamanho aproximado de $3 \mathrm{~mm}$ de CC, apresentam pleópodos rudimentares; enquanto os maiores que $4 \mathrm{~mm}$ de CC podem apresentar diferenciação dos pleópodos para machos ou para fêmeas. O crescimento relativo indicou diferença significativa na relação $L C$ vs. $L A(p<0,05)$, ou seja, uma mesma reta não se aplica para todas as categorias demográficas. O crescimento relativo de LC vs. LA apresentou-se alométrico positivo para as fêmeas, para os machos alométrico negativo e, para os indivíduos NS, isométrico. Tal relação é, portanto, eficiente para a diferenciação sexual de $L$. ferreirae a partir de $5 \mathrm{~mm}$ de LC. Contudo, os demais parâmetros corpóreos testados não indicaram diferenciação entre sexos ou fase de desenvolvimento. Esta é a primeira contribuição ao conhecimento da diferenciação sexual morfológica de $L$. ferreirae, a qual poderá servir de base a outros estudos de cunho ecológico e/ou de parentesco.
\end{abstract}

Palavras-chave: Majoidea, caranguejo-aranha, caracteres sexuais, crescimento, costa brasileira.

Financiamento: FAPESP \#2014/13770-1, \#2018/01659-0; CAPES/Ciências do Mar \# 23038.004310/2014-85; CNPq \# 308653/2014-9; CNPq bolsa Pq \#302691/2015-4. 